\title{
Climate change risks for severe storms in developing countries in the context of poverty and inequality in Cambodia
}

\author{
Halsnæs, Kirsten; Larsen, Morten Andreas Dahl; Kaspersen, Per Skougaard
}

Published in:

Natural Hazards

Link to article, DOI:

10.1007/s11069-018-3387-8

Publication date:

2018

Document Version

Peer reviewed version

Link back to DTU Orbit

Citation $(A P A)$ :

Halsnæs, K., Larsen, M. A. D., \& Kaspersen, P. S. (2018). Climate change risks for severe storms in developing countries in the context of poverty and inequality in Cambodia. Natural Hazards, 94(1), 261-278.

https://doi.org/10.1007/s11069-018-3387-8

\section{General rights}

Copyright and moral rights for the publications made accessible in the public portal are retained by the authors and/or other copyright owners and it is a condition of accessing publications that users recognise and abide by the legal requirements associated with these rights.

- Users may download and print one copy of any publication from the public portal for the purpose of private study or research.

- You may not further distribute the material or use it for any profit-making activity or commercial gain

- You may freely distribute the URL identifying the publication in the public portal 


\title{
Climate Change Risks for Severe Storms in Developing Countries in the context of Poverty and Inequality in Cambodia
}

\author{
Kirsten Halsnæs, ${ }^{1}$ Morten Andreas Dahl Larsen ${ }^{1 \#}$ and Per Skougaard Kaspersen ${ }^{1}$ \\ 1 - DTU Management Engineering, Produktionstorvet, Building 426, 2800 Kgs Lyngby, Denmark \\ \# - Corresponding author - mail: madla@dtu.dk
}

\begin{abstract}
Least developed countries are generally regarded as particularly sensitive to climate change due to among other vulnerable locations and low adaptation capabilities. In the present study, we address climate change hazards in least developed countries by presenting a methodological framework, which is suitable for the estimation damage costs as a function of risk aversion, equality, income distribution and climate scenario using state-of-the-art climate model projections. As a case study, the methodology is applied to study severe storms in Cambodia based on two future climate scenarios and data on historical damages from storm events, which are used as a proxy in performing a sensitivity analysis on all input parameters. For the assumptions and parameter ranges used here, the study shows a high sensitivity to the income distribution (reflected by discount rates) and risk aversion and smaller effects from equality measures and extreme wind climate scenario. We emphasize that the assumptions on risk aversion reflecting consumption smoothing possibilities of low-income households clearly depicts that climate risks can be particularly high as a consequence of poverty and therefore recommend that context-specific vulnerabilities and equity concerns in climate risk studies should be included when making assessments for least developed countries.
\end{abstract}

Keywords: poverty and climate change risks, extreme events, least developed countries, damage costs, equality, storms

\section{Introduction}

In the context of climate change risks in developing countries, policy-relevant studies face specific challenges in matching the available climate data to damage estimates and development projections, which can reflect policy-makers' concerns with climate change impacts on welfare and human livelihoods in the shorter term. Extreme weather events are already causing serious economic and human losses, with a particular high incidence rate among vulnerable population groups and economic sectors (Munich RE 2018). Statistical records of past extreme events show for some regions that the frequency and intensity of events have increased in recent decades, and serious damage has been reported (Young et al. 2011; Coumou and Rahmstorf 2012). The future projected intensities and frequencies of extreme wind occurrences for Southeast Asia is uncertain ranging from no-change to increases (Chang 2011).

The timing of climate impacts in relation to the timing of climate change departure and the variability of current weather patterns in different regions has been assessed by (Mora et al. 2013), concluding that departure impacts can be expected to occur from an early state in tropical regions due to their very fragile ecosystems and low human response capacities. The study concludes that regarding damages, there is a strong link between low income levels and early climate departure. Taking specific climate hazard exposure and socio-economic development into account (Patt et al. 2010) indicates that least developed countries (LDCs) 
will experience the greatest changes in vulnerability from now until 2050, underlining the need for urgent responses. Further, the issues of vulnerability to climate change have been highlighted specifically for Asian LDCs in particular (Penning-Rowsell et al. 2013; Barbier 2015; Wei et al. 2016) as well as for constructing future scenarios (Birkmann et al. 2015). Along the same lines of thinking, other studies (Zou and Wei 2010; IPCC 2014a) conclude that LDCs are particularly vulnerable due to the fragility of human settlements, low incomes, weak infrastructure and institutions, and a low level of capacity for coping with climate change. The effect of past disaster experiences and corresponding capabilities to reduce natural damages have however been found to be stronger for lower income countries compared to high income countries (Onuma et al. 2017). In this light, we therefore emphasize the importance in studying the impacts and implications of extreme events in LDCs despite uncertainties and limitations in data quality and availability, as well as the inherent challenges in implementing adaptation practices such as within-country priorities and entry points, as put forward by (Conway and Mustelin 2014).

The climatic projections that are used to drive climate adaptation measures include a certain degree of noise arising from natural variability, especially in the short term (Hawkins and Sutton 2009) and for extreme events (Katz 2010), whereas economic development and emissions scenarios form the key uncertainties for longer term studies (Hawkins and Sutton 2009). In addition, such hazards may be related to variables and processes that are poorly depicted even in present-day state-of-the-art climate models. The combination of several impacts, such as wind speed, wind direction, wind duration, tides and precipitation, which altogether form a hazardous impact, can also be difficult to reproduce properly (Wahl et al. 2015). Altogether, climate change impact studies indicate a challenge in the trade-off between uncertainty and time horizon, as a few recent studies have shown for LDCs (Vermeulen et al. 2013; Møller et al. 2017).

In the present study, we focus on damage from extreme climate events in the form of storms in Cambodia, where they have been a main hazard in recent decades, a pattern that is expected to continue into the future (Ministry of Environment 2005, 2006; DanChurchAid/Christian Aid (DCA/CA) 2011; IPCC 2014b). Cambodia is an LDC with a per capita Gross National Income of US\$ 1,140 in 2016 of which agriculture accounted for 27 percent of GDP (World Bank 2017). In 2013, 17 percent of the population were living below the national poverty line (World Bank 2017). Cambodia's population in that year was 14.7 million (National Institute of Statistics 2013), of which the rural population accounted for 79 percent. Cambodia is regarded as highly vulnerable to climate change impacts and was classified as the $25^{\text {th }}$ highest country with regards to losses from extreme climate events in 2016 (measured as a percentage of purchasing power GDP - 0.8\%) in the Global Climate Risk Index (Harmeling et al. 2012) and is therefore relevant as a case study also due to data availability.

For purposes of the present analysis, we introduce a methodological framework for the assessment of damage costs from projected climate extremes with the aim of reflecting issues of risk aversion, equality and income distribution in a developing country context. The methodological framework applied here to study climate risks for Cambodia represents a specific application of a welfare economic approach ((IPCC 2014c), chapter 3) in which damage from extreme climate events is assessed in the context of LDCs in conjunction with uncertainties related to climate change scenarios, damage costs and, in particular, economic assumptions.

Our analysis integrates state-of-the-art climate modelling and impact assessments in respect of climate projections of storms and associated impacts. Subsequently, the economic consequences are assessed in relation to human settlements and geographical areas by also addressing risk aversion and inequality issues. In this study, a bottom-up approach is used for 
damage costs, assigning cost parameters to assets that are at risk under storm events in Cambodia. Damage costs are transformed into a measure of "willingness to pay" (WTP) in order to avoid damage, risk preferences being integrated with the income equality of the victims in order to reflect special issues of climate extremes in LDCs.

Given limited data availability in terms of both climate scenarios and damage costs (including geographical variations), we are focusing on providing insights into how short-term climate change, climate-model and climate-scenario uncertainties and poverty influence risk assessments. We conduct a sensitivity analysis in order to illustrate how the vulnerabilities of poor households can be reflected in damage estimates of extreme climate events and to identify a number of key assumptions that distinguish assessments of damage costs from climate extremes in developed and least-developed countries respectively.

\section{$2 \quad$ Methods}

\section{$2.1 \quad$ Methodological Framework}

In the following we present the major analytical elements in our study of climate change vulnerabilities in Cambodia, including damage cost calculations, future storm patterns, storm damage, and poverty and risk aversion.

In the methodology presented here, social welfare forms the damage cost assessment component (reflecting, e.g., the perspectives of societies in relation to climate change impacts), where the total damage cost is an aggregate measure of damage costs to individuals.

We particularly want to reflect how extreme events can impose risks on LDCs, and reflect the key issue of low probability and high potential damage due to low coping capacity by lowincome households. Our methodological framework accordingly is adjusted to reflect preferences of society towards risk aversion and uncertainties in the context of developing countries (Heal and Kriström 2002; Weitzman 2011). We include risk aversion in the methodology by adding a (risk aversion) coefficient to the social welfare function. Risk aversion is included in the methodology to reflect the behaviour of individuals in cases of uncertainty such as for extreme storm event probabilities. In the case of minimizing the potential hazards of such uncertain events, the risk aversion could often lead to a high willingness to pay for adaptation measures. In LDCs where access to capital and thus consumption smoothing is limited in poor households, the literature suggests that these households could be particularly risk-averse in relation to the possibility of losing future consumption opportunities (Gollier 2001; Weitzman 2011). We also apply an income-equality factor to the estimates of damage in Cambodia to reflect the fact that damage in terms of welfare counts more for lower income households than higher-income households (Markandaya 1998). In the present study, we use the term 'least-developed country' as defined by the United Nations (United Nations 2018) and 'developing country' as defined by the International Statistics Institute (International Statistics Institute 2018) holding 47 and 139 countries respectively (there among Cambodia). We also refer to 'low-income households', which has several definitions related to income level, compared to the median or poverty line, and is here used in general to reflect a certain poorer share of the population within the country in question.

\section{$2.2 \quad$ Damage Cost Calculations}

Our damage cost assessment is based on traditional concepts of economic welfare, where the utility of losing consumption caused by climate extremes is measured. The concepts are 
briefly introduced in terms of equations (see (IPCC 2014c), chapter 3, for more on the economic welfare concept applied to studies of costing climate change).

As a basis for measuring damage costs, we assume a social welfare function $V$, where $u\left(c_{t}\right)=$ $V_{t}$ is the contribution to the social welfare function of generation $t$ consuming $c_{t}$. The future consumption depends on the probability of climate events and we therefore calculate the expected value $E u\left(c_{t}\right)$ of consumption as follows:

$\mathrm{V}=\sum_{t=0}^{\infty} E u\left(c_{t}\right) d(t)($ eq. 1$)$

where $\mathrm{u}_{\mathrm{ct}}$ is the contribution to the social welfare of consumption $c_{t}$ at time t. The factor $d$ is a discount factor, which reflects our preferences for economic flows arriving at different points in time (IPCC 2005). We apply a risk aversion coefficient to the evaluation of damage, assuming a constant risk aversion coefficient as defined by (Arrow 1965):

$A(w)=-U^{\prime \prime}(w) / U^{\prime}(w)($ eq. 2$)$

where $A(w)$ is the risk aversion associated with a given change in social welfare and $U(w)$ its utility. In the case of a utility function, which is a polynomial of order $n$, the risk aversion coefficient takes the form:

$A(w)=n x^{n-1}($ eq. 3$)$

To the authors' knowledge, there are no specific studies of attitudes to the risks of climate change, which can be used to determine the level of the risk aversion coefficients. In our study, we have chosen to use risk aversion values of one to reflect risk neutrality, and three to reflect risk aversion.

We apply an inequality aversion parameter (epsilon) based on (Markandaya 1998), to reflect the relationship between the average national income and the incomes of those suffering damage. The definition of the inequality is:

$$
\frac{\partial W}{\partial Y_{i}}=\left[\frac{-}{Y}\right]^{\varepsilon} \text { (eq. 4) }
$$

where $W$ is social welfare, $Y_{i}$ is the income of an individual, and $\bar{Y}$ is representing the average income (fixed to a value of 1 ).

Combining the welfare loss of consumption loss by climate events, risk aversion and inequality aversion to damage, we can then calculate the welfare economic perspective of damage costs (WTP) as:

WTP $=$ damage costs $*$ risk aversion factor $*$ inequality weight to income classes (eq. 5)

We apply our methodological framework to the assessment of damages from extreme storms in Cambodia as a basis for discussing key uncertainties and economic assumptions in the specific context of developing countries.

\subsection{Scenarios of Storm Frequency and Intensity}

\subsubsection{Climate Change Data}


The climate data input that form the basis for evaluating future storms in terms of wind patterns is based on the evaluation of data from three sources. One dataset includes the IBTrACS International Best Track Archive data set (Knapp et al. 2010), which is included here for comparison with other model-based sources. IBTrACS data reflect the historical geographical tracks of tropical cyclones and corresponding wind speeds and cover the historical period from the middle of the previous century (for global coverage) until the present day. The second dataset, CMIP5, is a multi-model global climate model ensemble archive (Taylor et al. 2012). The third dataset, CORDEX, is a regional climate model experiment framework (Giorgi and Gutowski 2015) covering selected geographical regions in fourteen domains with standardized coverage and grid structure. The historical wind data from the three source data sets of both occurrences and wind speeds are shown in Figure 1A. The same analysis is applied to CMIP5 and CORDEX data: The maximum daily near-surface wind speed (the 'sfcwindmax' variable) is used here as a measure to describe future wind speeds over Cambodia. For CMIP5, a subset ensemble of six models is randomly chosen (see Table 1), albeit from different source institutions, out of the 51 total available simulations from 25 different models, as is also done in other studies such as (Hemer and Trenham 2016). For CORDEX, three of the model domains cover Cambodia (South Asia, Southeast Asia and East Asia (EAS)). Of these, only data from the EAS domain is used, since Cambodia is located along the model domain boundary in the remaining two, which is known for its potential to degrade model performance (Larsen et al. 2013). For the EAS model domain, 'sfcwindmax' output is available for five combinations of global and regional climate models (GCMs/RCMs), which are all included in the ensemble assessed here. Further, to depict the spatial patterns of wind speeds over Cambodia, the 'wsgsmax' variable is extracted to visualize gust wind speeds (Figure 1).

\begin{tabular}{|c|c|c|c|c|}
\hline \multicolumn{5}{|c|}{ IBTrACS (Knapp et al. 2010) } \\
\hline \multirow{2}{*}{\multicolumn{5}{|c|}{$\begin{array}{l}\text { Collaboration between multipl } \\
\text { CMIP5 (Taylor et al. 2012) }\end{array}$}} \\
\hline & & & & \\
\hline \multicolumn{2}{|c|}{ GCM } & Source institute & SfcWindMax & \\
\hline \multicolumn{2}{|l|}{ CNRM-CM5 } & Meteo France & $\mathrm{x}$ & \\
\hline \multicolumn{2}{|l|}{ GFDL-ESM2G } & GFDL & $\mathrm{x}$ & \\
\hline \multicolumn{2}{|l|}{ HadGEM2-ES } & Met Office Hadley Centre & $\mathrm{x}$ & \\
\hline \multicolumn{2}{|l|}{ IPSL-CM5A } & Intitut Pierre et Simon Laplace & $\mathrm{x}$ & \\
\hline \multicolumn{2}{|l|}{ MIROC5 } & University of Tokyo & $\mathrm{x}$ & \\
\hline \multicolumn{2}{|l|}{ MPI-ESM-MR } & Max Planck Institute for Meteorology & $\mathrm{x}$ & \\
\hline \multicolumn{5}{|c|}{ CORDEX (Giorgi and Gutowski 2015) } \\
\hline GCM & RCM & Source institute & SfcWindMax & WsgsMax \\
\hline EC-Earth & HIRHAM5 & DMI & $\mathrm{x}$ & \\
\hline EC-Earth & CCLM5 & CLM Community & $\mathrm{x}$ & $\mathrm{x}$ \\
\hline HadGEM2-ES & CCLM5 & Met Office Hadley Centre & $\mathrm{x}$ & $\mathrm{x}$ \\
\hline MPI-ESM-LR & CCLM5 & CLM Community & $\mathrm{x}$ & $\mathrm{x}$ \\
\hline CNRM-CM5 & CCLM5 & CLM Community & $\mathrm{x}$ & $\mathrm{x}$ \\
\hline
\end{tabular}

Table 1. Models, model combinations and variables used from the CMIP5 and CORDEX databases. 

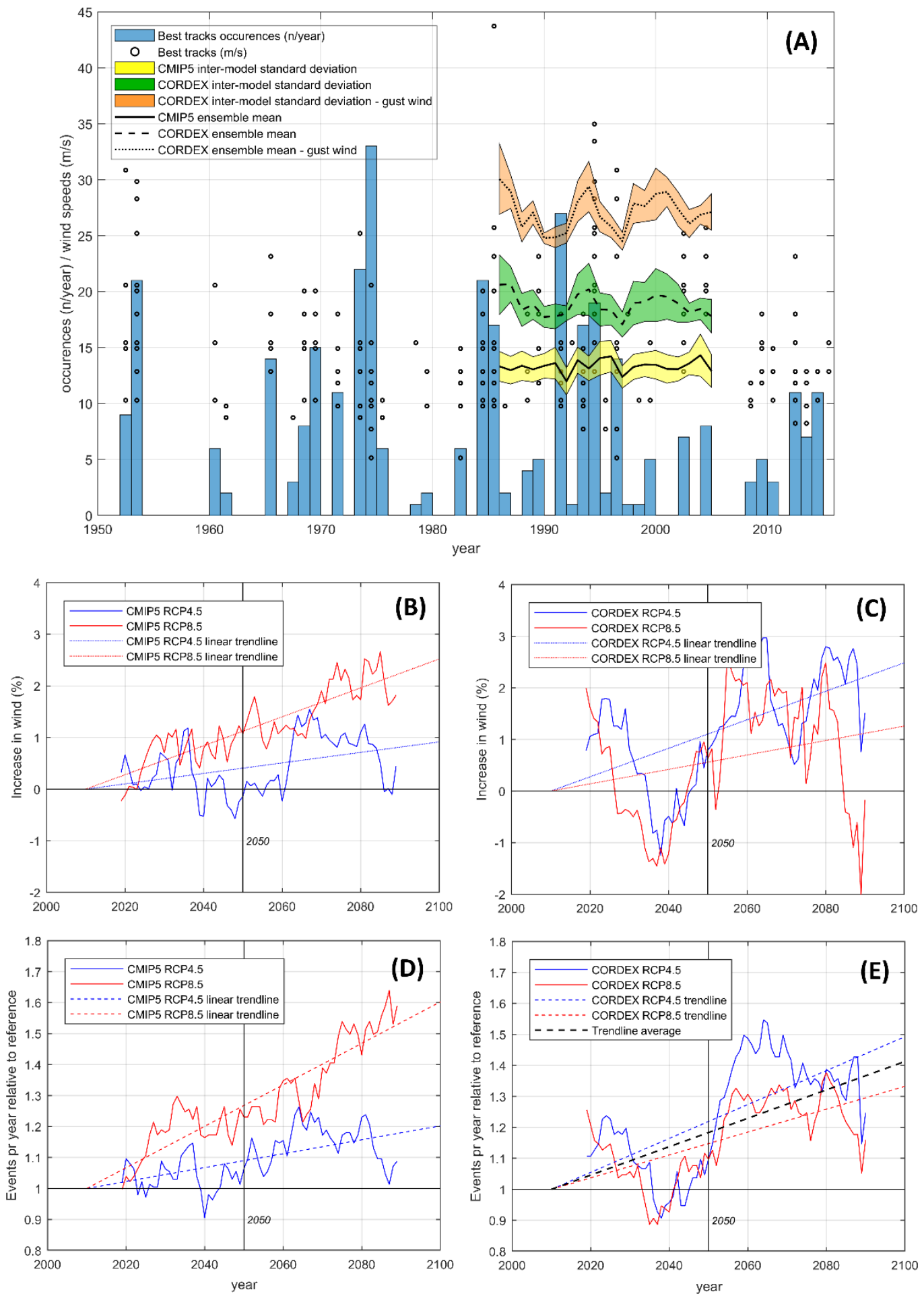

Figure 1. Plot A: IBTrACKS wind speeds and occurrences (1950-2016), CMIP5 and CORDEX daily maximum wind speeds and CORDEX gust wind speeds (all 1986-2005). Plots B and C: the relative increase in wind speed for CMIP5 and CORDEX respectively from 1986-2005 to 2010-2100 in twenty-year running means plotted around the central year. Plots $D$ and $E$ : the index level of the number of 99.73 percentile exceedances (similar models, years and plotting as for $B$ and $C$ ). 


\subsubsection{Projections of extreme winds}

To obtain a quantitative measure of future extreme winds and associated damage costs, changes from the 1986-2005 reference period (historical data driven by GCMs - Table 1) relative to the 2010-2100 period (using RCP4.5 and RCP8.5) are assessed for the CMIP5 (six-model) and CORDEX (five-model) ensembles. Specifically, the daily maximum wind speed over Cambodia is extracted for both the reference and future periods. To reflect extreme cases of more sustained winds, the 99.73 percentile, corresponding to one event (daily data) per year, is calculated for the reference period for each individual model within the CMIP5/CORDEX model ensembles. In the following analysis, this input also reflects the probability of a storm event and thereby the expected risk of storm damage, as referred to in Section 2.2. Based on this percentile (once a year), two metrics are calculated:

I. The (model mean) relative increase in the 99.73 percentile wind speed for the future period in running twenty-year periods (Figure 1B/C).

II. The (model mean) number of events exceeding the 99.73 percentile (calculated for the historical period per model prior to calculating the ensemble mean) using the same running mean period (Figure 1D/E). These calculations are normalized by setting year 2010 to index 1.

To provide a measure of future wind patterns for the damage analysis, trends for both measures (speed and the number of exceedances) are calculated using simple linear regression over the 2010-2100 period. Since we are addressing the tail of the probability distributions of wind patterns, the period length is chosen to ensure sufficient temporal coverage to identify a potential signal, as compared to noise from natural variability. For the damage cost calculations, however, we focus on the timeframe up until 2050, due to inherent uncertainties in projecting economic development and vulnerability over a very long timeframe of up to 2100. The climate data extracted for the year 2050, however, are based on long-term trends until 2100 (Figure 1).

For the first measure, absolute wind speeds, little change is seen over Cambodia towards 2050/2100 for both data sources (CORDEX and CMIP5) and future scenarios (RCP4.5 and RCP8.5), with relative changes in the order of $0-2.5 \%$ change for the year 2100 (Figure 1 $\mathrm{C}+\mathrm{B}$ respectively). For the second measure, the number of occurrences, index values of 1.09 and 1.27, are seen for CMIP5, RCP4.5 and RCP8.5 respectively, whereas index values of 1.15 and 1.22 are seen for CORDEX, RCP4.5 and RCP8.5 respectively (all for year 2050; see Figure 1, A-D). For CMIP5, the signal of change in occurrences of extreme winds in RCP4.5 and RCP8.5 diverge considerably after 2065, with larger changes observed under RCP8.5 in the long term. The same trend is not present for CORDEX, as the signal is comparable for both scenarios in both the short and long terms.

For CORDEX, slightly larger increases in both metrics are seen for RCP4.5 compared to RCP8.5, although the patterns are largely similar. This is likely to be related to the high percentile used here (one event a year) which causes the results to be affected by model variability, which is also supported when reducing this pattern with a decreased percentile (not shown). For wind speeds, the pattern between RCP4.5 and RCP8.5 is also likely to be related to the weak trend or its absence.

Based on the above, two climate change scenarios are used to depict the future frequency of extreme storms (99.73 percentile) in Cambodia: 
I. Climate Scenario 1, a scenario based on the CORDEX analysis (Figure 1E) showing a mean ensemble increase in the occurrence of extreme storms with an index value of 1.19 between both RCPs in 2050 .

II. Climate Scenario 2, a scenario based on the CMIP5 analysis (Figure 1D) showing a mean ensemble increase in the occurrence of extreme storms of index 1.27 in 2050 for the high-emissions RCP8.5 scenario.

\section{$2.4 \quad$ Damages from Storms}

\subsubsection{Damages from Historical Events}

Access to storm damage data for Cambodia is very limited, but some data on storm events and related damage in relation to victims, fatalities and houses are available in the UNDP Disaster Information System (UNDP 2015) covering Cambodia as one entity. This relies on reported data from local disaster events and does not distinguish between different storm intensities or damage levels. One criteria for the UNDP data is that events can only be included if they have been reported as part of disaster emergency assistance because of specific damage. This implies that the UNDP systems data reports cannot be seen as a direct measure of the number of storm events, but rather are a measure of the extent of damage from storm events for the storms, which have been reported as part of an emergency response process in Cambodia. It is important to recognize the inherent uncertainties of such a data system in terms of both the quality and the consistency of the reported data, as well as the inclusion of relevant events. Despite these uncertainties, we use the UNDP Disaster Information System as an indicator of storm damage in Cambodia since no other damage data system is currently available.

The UNDP Disaster Information System holds information on the $1996+2000-2014$ yearly occurrences of storms and the corresponding number of houses and victims affected (Figure 2 ). For the reported damage data, the number of victims increases to a high level in the last part of the period from 2007 to 2014, which may be related to the incorporation period of the reporting system throughout Cambodia. For this reason, we employ damage indicators per Storm, as opposed to using the trends occurring in the data set.

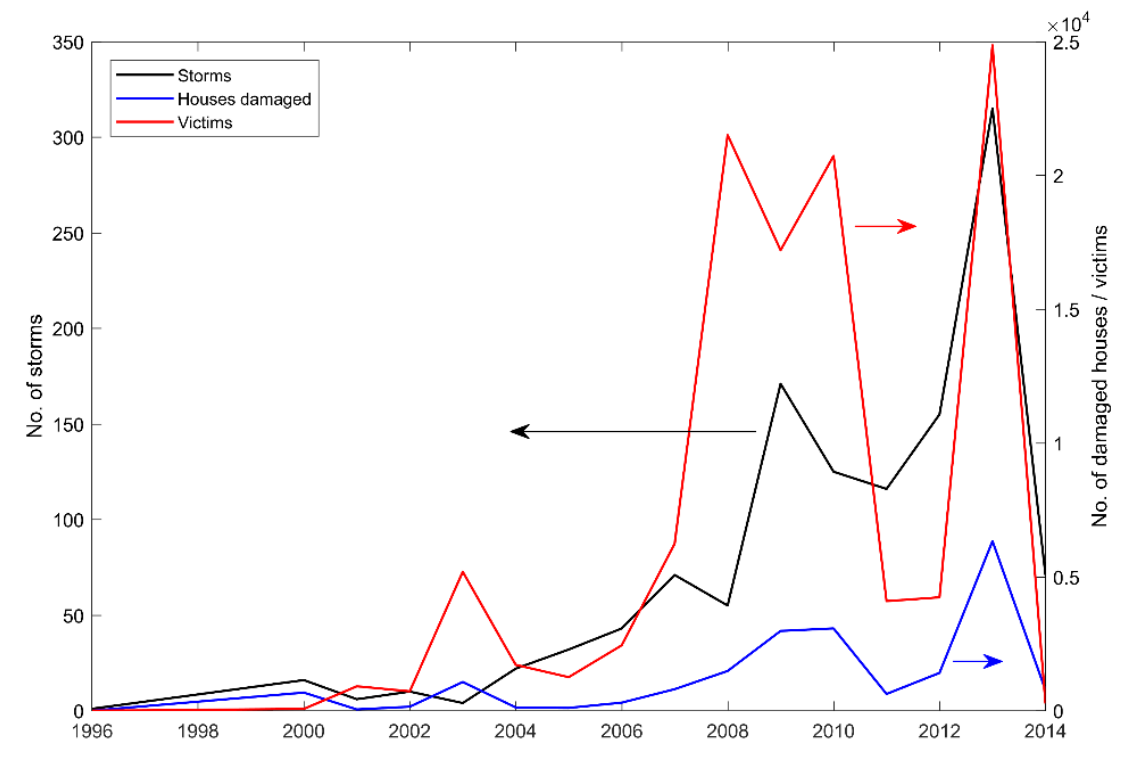

Figure 2. Development in the number of damaged houses and storm victims in Cambodia reported in the UNDP disaster information system for 1996-2014 (UNDP 2015). Arrows point to the relevant y-axis. 
The data reports shown in Figure 2 cannot be used as an absolute measure of storm damage since some events and damage reports may be missing in the database, and the definition of a victim or damage to buildings may vary across data reports. A representative damage proxy for the storm events have therefore been chosen calculated as the average of the number of storm events and the related victims for the period 1996-2014. Further, this damage proxy is used to forecast the number of victims associated with storms in the future.

Using a quantitative measure of victims as a proxy for damage costs rather than monetary values implicitly assumes that the economic value of damage to individual houses and people is constant over time in terms of both the magnitude of the damage and the related costs. In this way, the number of incidents is used to represent the damage caused by an event. There are many limitations to such an approach, as damage values and storm consequences might change over time. These uncertainties and future changes to damage values can both tend to increase and decrease damage cost estimates: On one hand, economic development tends to create higher asset values and could therefore increase damage costs by extreme climate events. On the other hand, development could tend to decrease the vulnerability of people and assets through increased awareness and investments in risk-reduction measures.

\subsubsection{Projections of Damage from Storms}

For the damage cost assessment, the number of victims have been chosen as a representative indicator of damages since the aggregation of multiple indicators would not be feasible (i.e. houses destroyed, damaged and victims).

Based on the average proxy of damage (victims) per storm event amounting to 99 for the period 1996 to 2014 and the two climate scenarios, the number of victims associated with storms have been projected until the year 2050 as shown in Figure 3. The two alternative climate scenarios described in the section above are used in order to compare the damage cost proxy represented by the victims of storms, which, given Climate Scenarios 1 and 2, could be affected by storms in 2050. We use the year 2050 due to the greater uncertainties regarding the damage proxy on storm victims with a longer timeframe.

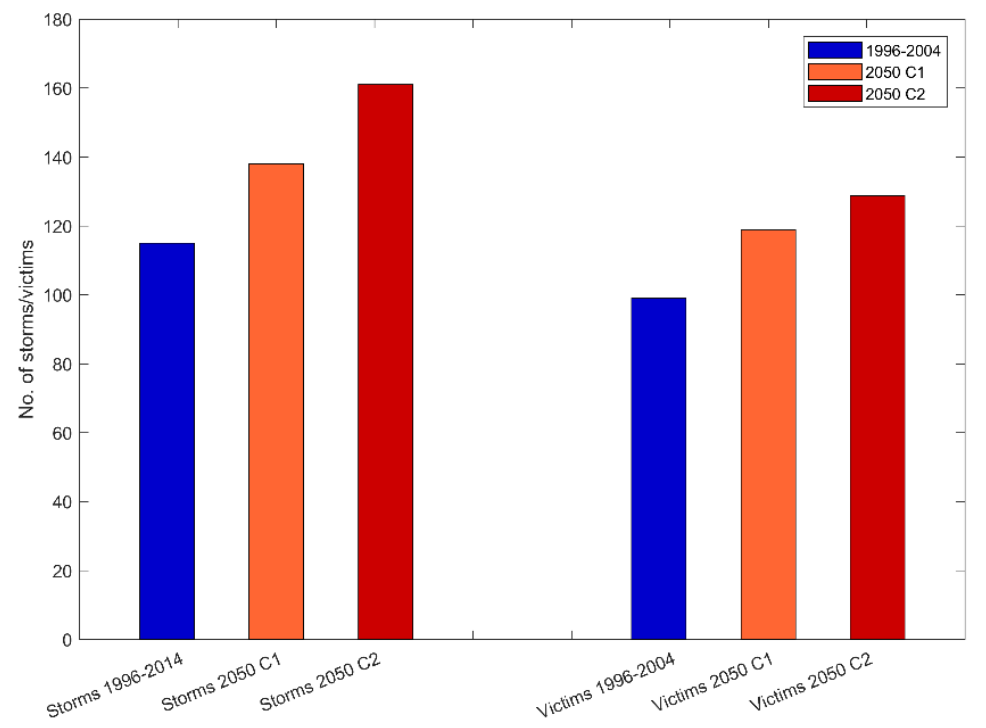

Figure 3. Projections of victims by storms in Cambodia in 2050 based on average numbers of victims per storm in UNDP data records for the period 1996-2014, with storm projections for climate scenarios (C1) and (C2) for the period 2015-2050. 


\section{$2.5 \quad$ Poverty and Risk Aversion}

In the following, we combine the damage cost proxy given the climate scenarios with alternative assumptions for risk aversion and inequality weights to income classes (both components are a part of WTP equation No. 5, described above).

Damage cost proxy

To provide a proxy for damage costs, data on victims reported for Cambodia in the period 1996 to 2014 are used. Using, for example, damaged houses instead showing a similar pattern would have resulted in similar results. The damage cost proxy index value provides us with the following values for the period 2015-2050, stated as the number of victims relative to the 19962014 average:

- $\quad$ Climate Scenario 1 damage cost proxy = 1.19

- $\quad$ Climate Scenario 2 damage cost proxy = 1.27

\section{Risk aversion}

We apply a risk aversion coefficient of three and an alternative coefficient of one representing risk neutrality to reflect risk aversion.

\section{Inequality weight to income classes}

We apply income distribution weights of 1 and 1.75 respectively to reflect two different assumptions in the damage assessment given weight to low income groups in the damage assessment. The weight of one implies that all individuals are valued as having an income equal to the average income in Cambodia, while the weight of 1.75 assigns a higher value to lowincome groups. We are basing our income distribution weights on consumption data in the Cambodian government household consumption survey from 2009 (CRDI 2013) which is on both a national level as well as for the capital of Phnom Penh, other urban areas and rural areas (Figure 4).

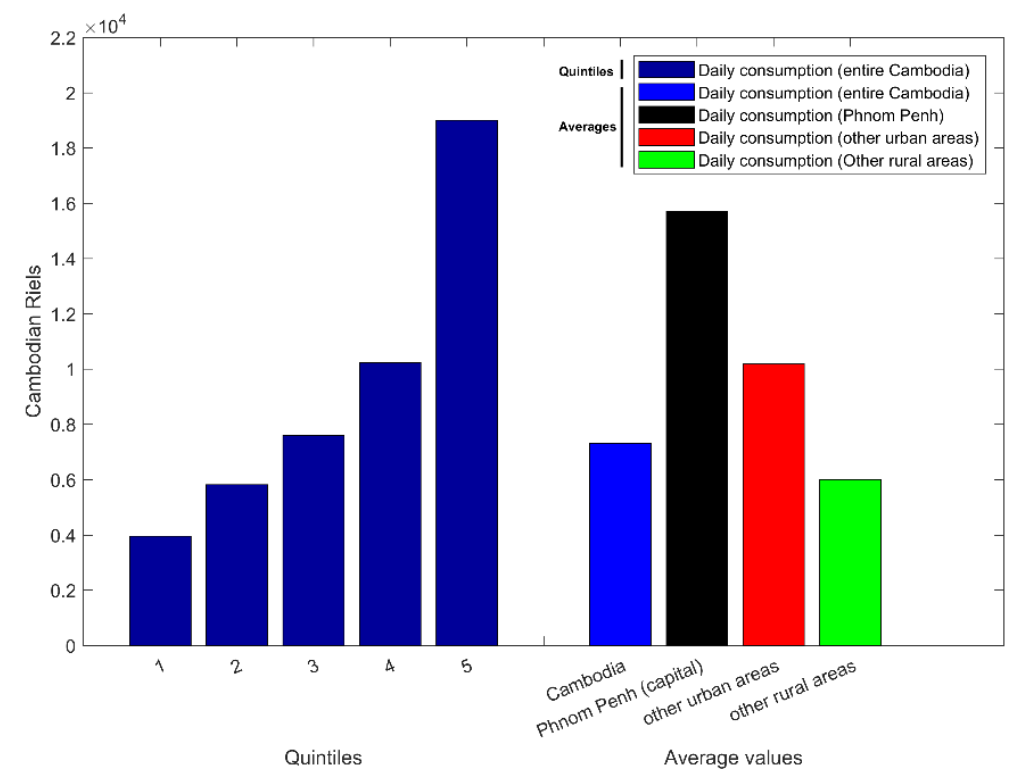

Figure 4. The distribution of Cambodian household consumption in different quintiles (left) and averages for different urban and rural areas. 
Based on the data shown in Figure 4, we assume that $60 \%$ of the damaged households have a daily household consumption corresponding to the average consumption in the two lowest quintiles, $30 \%$ have average consumption (quintile 3 ), and $10 \%$ have consumption corresponding to the average consumption in quantiles 4 and 5 . The average consumption in quintiles 1 and 2 combined is 4886 Riels, corresponding to $67 \%$ of total average consumption for Cambodia, while the average consumption in quintiles 4 and 5 is 2.6 times total average consumption in Cambodia. The inequality factors then become:

- With income distribution weight $1: 0.60 *(1 / 0.67)^{1}+0.30 *(1 / 1)^{1}+0.10 *(1 / 2.6)^{1}=$

1.2

- With income distribution weight 1.75: $0.60 *(1 / 0.67)^{1.75}+0.30 *(1 / 1)^{1.75}+0.10 *$ $(1 / 2.6)^{1.75}=1.5$

Climate scenarios 1 and 2 are combined in a sensitivity analysis in combination with assumptions about risk aversion and weights to income inequalities (see Table 2).

The risk calculations are employ Net Present values (NPV) for a 36-year timeframe. The NPVs then serve as proxy values of damage based on climate scenario assumptions for the period 2014 to 2050. The NPV values are calculated using a high discount rate of 7\% and a lower discount rate of $5 \%$.

\begin{tabular}{|l|l|l|}
\hline & Climate Scenario 1 & Climate Scenario 2 \\
\hline Damage cost proxy & 1.19 & 1.27 \\
\hline Risk aversion high & 3 & 3 \\
\hline Risk aversion neutral & 1 & 1 \\
\hline Inequality factor high & 1.5 & 1.5 \\
\hline Inequality factor low & 1.2 & 1.2 \\
\hline
\end{tabular}

Table 2. Combinations of assumptions applied to the damage cost proxies in terms of climate scenarios, risk aversion and income inequality factors.

\section{$3 \quad$ Results and Discussion}

The modelling of extreme winds is an immense challenge which is quite well described in literature (IPCC 2014b) and is dependent not just on very local scale features, including orography (Herrmann et al. 2011), but also, for example, the quality of GCM forcings (Jury et al. 2015). In the present paper, we perform storm-induced damage cost calculations based on both RCM and GCM projections. The use of RCMs in the analysis of extreme winds has in general been performed in studies such as (Rockel and Woth 2007; Jiang et al. 2010; Kunz et al. 2010). Further, CORDEX simulations, like those used in the present study, have been used to assess future wind patterns (Tobin et al. 2016) and successfully reproduce tropical cyclone features (Jin et al. 2016), as well as other hazard events (Púčik et al. 2017). For RCMs, a typical assumption is that an increased resolution is better able to resolve smaller scale spatio-temporal features contributing to the generation of extreme winds. (Pryor et al. 2012) argue that these scales are still poorly represented in most RCMs, despite showing an improved reproduction of extreme winds for finer scale resolution runs using the RCA3 RCM in the range of 50 to $6.25 \mathrm{~km}$. Supporting the use of RCMs over GCMs, (Kumar et al. 2015) showed a generally poor reproduction of local scale features and absolute values when assessing high or extreme winds from the 'sfcwindmax' variable in fifteen selected CMIP5 (global) climate models. Similarly, (Camargo 2014; Kumar et al. 2015) showed a poor 
CMIP5 reproduction of observed cyclone patterns, though with better performances regarding spatial patterns rather than frequencies. The increase in the number of severe events up until 2050 relative to 2010, like that found in the present study, is closely in line with the findings of (Ren and Leslie 2015) using a tropical cyclone tracker to project future extreme wind conditions over Western Australia, showing an increase of factor of 1.3 (events/year) from 2005 to 2050. The relation between IBTrACKS wind speeds and occurrences, CMIP5 and CORDEX daily maximum wind speeds and CORDEX gust wind speeds can be seen in Figure 1A, which reveals the effect of model resolution on simulated wind speeds. In summary, the analysis of climate data suggests that more trust should be put in outputs from regional climate models like those represented here by Climate Scenario 1 (using both RCP4.5 and 8.5) than in the case of Climate Scenario 2, which is solely based on runs by GCMs under the CMIP5 for the RCP8.5 climate scenario.

Very few studies on the impacts of future extreme weather events as a consequence of climate change exist and most have been completed for developed countries (IPCC 2007, 2014a). We here argue that low-income families are particularly vulnerable to extreme climate events, and the location of extreme storm events in relation to income distribution is therefore a key element in assessing vulnerabilities. Figure 5 shows the geographical distribution of 99.73 percentile gust wind speeds (1986-2005) and population densities and poverty levels for 20102011 (Ministry of Planning 2012). From the map (Figure 5A), it is clear that the highest wind speeds have occurred towards the coast in the south-western parts of the country and to some extent towards its eastern and western borders. In this respect, a high share of low-income households are located towards the coast, although the population density is also relatively low. In the areas surrounding Phnom Penh, where poverty is also widespread and incomes are low, moderate wind speeds also occur. In a similar analysis (not shown), the future projected wind speeds were analysed showing similar geographical patterns as shown here. Seen in the context of future economic development, the relative contribution to GDP of primary economic sectors like agriculture and fishery, which are predominant in particularly vulnerable areas, can be expected to decrease. This implies that the conclusions regarding welfare loss associated with extreme climate events will look different over time depending on national versus regional geographical scales (DanChurchAid/Christian Aid (DCA/CA) 2011). 

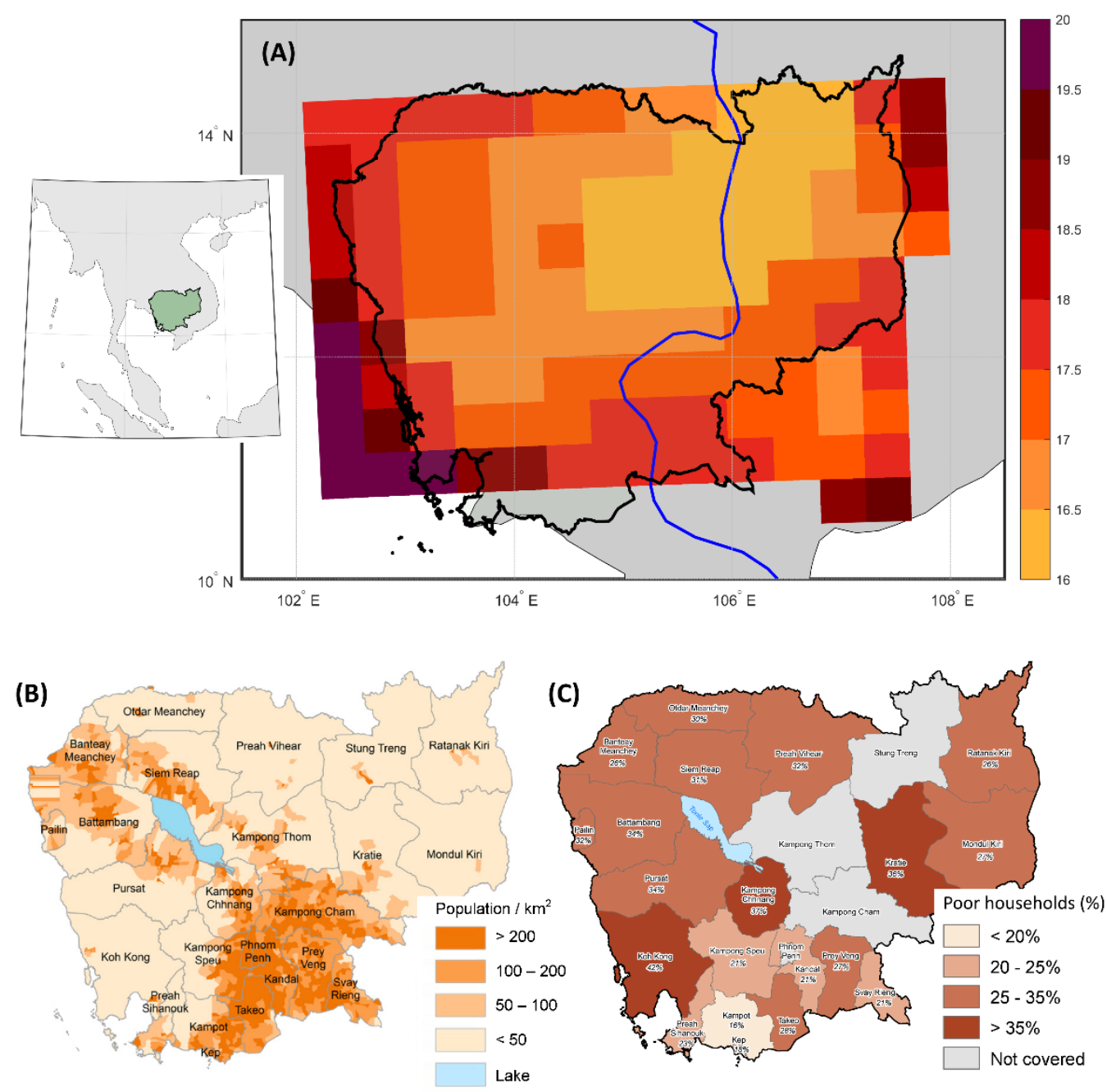

Figure 5. Plot A: The 99.73 percentile gust wind speed (wsgsmax) over Cambodia for 1986-2005 for Climate Scenario 1 - see Table 1 for model description. Plot B: Cambodia's population density (2010-2011). Plot C: the percentage of poor household (levels one and two) in Cambodia (2010-2011). Three regions are missing. Mekong River is plotted in blue. The latter two plots were reproduced from (Ministry of Planning 2012).

Figure 6 shows the resulting NPV damage proxy results for both climate change scenarios for the range of assumptions used here regarding risk aversion and income-inequality weights (Table 2) using a 5\% and a 7\% discount rate. Here we are comparing the damage proxy for Climate Scenarios 1 and 2. From the results, it is obvious that the damage proxy for storms is critically dependent on assumptions about discount rates, income equalities and risk aversion. This corresponds to the findings of (Halsnæs et al. 2015), who, through a sensitivity analysis of 32 combinations of climate scenarios and economic assumptions, concluded that future climate scenarios and the economic assumptions used are both very important in determining the risks of extreme climate events and, thus, the level of cost-effective adaptation. The largest NPV of the damage proxy is achieved when a high-risk aversion coefficient of three and a high-income inequality factor are used. If the assumptions applied to the damage cost value are considered one by one, the risk aversion coefficient in our application has the largest impact on the damage proxy, followed by the income equality factor. Variations in our assumptions about discount rates, as well as the two climate scenarios, have a smaller impact on the damage cost proxy. This conclusion reflects the fact that it is important to consider specific issues in 
relation to damage cost assessments in LDCs countries and that the degree or nature of climate change is not the most important issue in this respect.

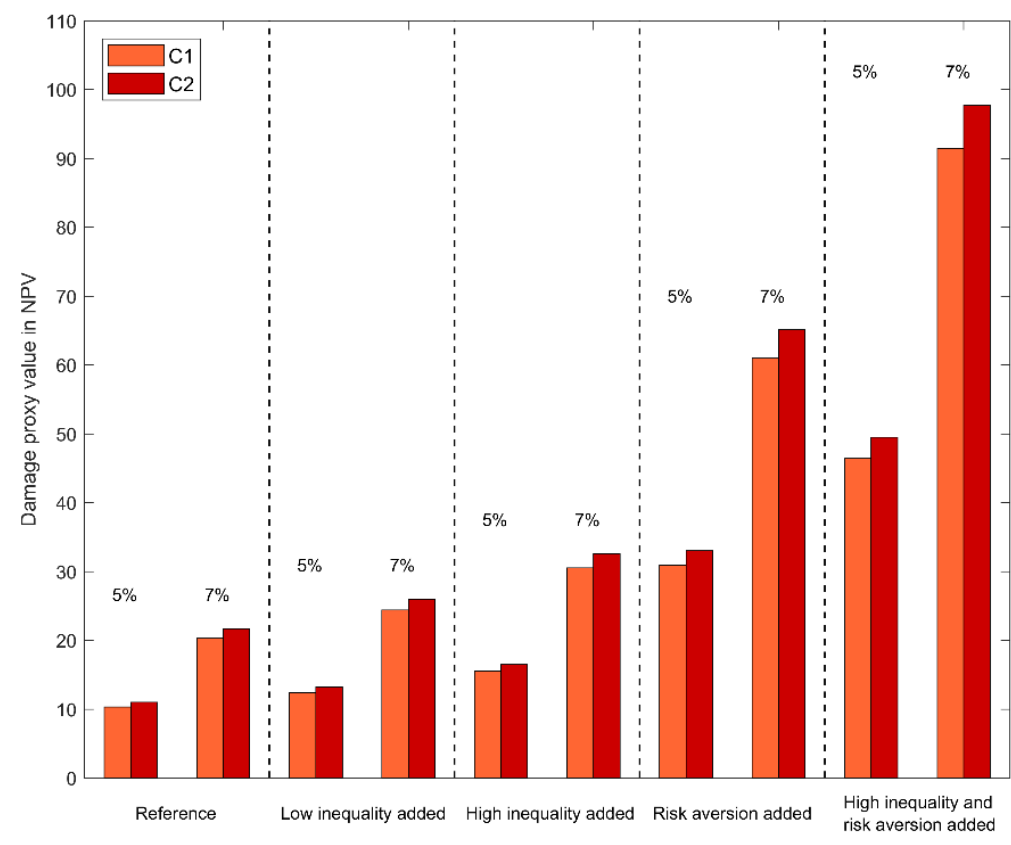

Figure 6. Damage proxy levels in 2014 (in NPV) for avoided damage using different combinations of inequality factors, risk aversion and climate scenarios, using discount rates of 5\% and $7 \%$. See Table 2 for different combinations of assumptions and climate scenarios.

In conclusion, the sensitivity analysis demonstrates that damage costs associated with extreme events for LDCs (as for severe storms in Cambodia) strongly depend on how the incomes of storm victims are included in the analysis. Low-income households often live in geographical areas, which are prone to climate extremes and with houses poorly protected against storms. Since the most vulnerable households tend to be poor, cost-benefit analyses could conclude that the assets lost typically have a low economic value in absolute terms. The present study, however, shows that the utility of lost consumption because of extreme climate events in LDCs may have a high value in terms of missed welfare. Following these arguments, climate policies and international finance must assign a high priority to adaptation investments in vulnerable areas with a high density of low-income households in LDCs as seen from an equity perspective.

\section{Conclusions}

Low incomes, weak infrastructure and limited institutional capacity for coping with climate change provides a background for making developing countries very vulnerable to climate change. Extreme events that have occurred in recent decades point to the threat of an increasing frequency of incidents and damage. Despite uncertainties about the attribution of such events to climate change, it is therefore important to strengthen data and methodological frameworks further for assessing risks in vulnerable countries.

In this paper, we employed specific assumptions on index-based projections of extreme winds, WTP values for avoided damage reflecting risk aversion and inequality factors as used to increase the weight of damage and associated income losses in the context of LDCs and poor households. We show that by applying these factor perturbations in the sensitivity analysis, a substantial influence is given to the WTP estimates of avoided damages as well as to the discount rate level. This indicates that the nature and extent of these assumptions is very 
important seen in the context of economic arguments for climate risk management in countries like Cambodia. The study contains certain uncertainties in relation to climate data on storm patterns and the damage associated with storm events. A set of relatively simple assumptions have therefore been adopted based on available climate projections and national damage reports, the implication being that the solidity of the specific magnitude of climate risks and adaptation costs in LDCs is limited. However, the study forms a relevant contribution to existing literature by clearly highlighting the range of critical assumptions made and further reflects the resulting inequality and vulnerability outcomes. The same approach could be applied to other types of high-impact events and other case regions.

\section{References}

Arrow K (1965) The theory of risk aversion. In: Aspects of the Theory of Risk Bearing

Barbier EB (2015) Climate change impacts on rural poverty in low-elevation coastal zones. Estuar Coast Shelf Sci 165:A1-A13 . doi: 10.1016/j.ecss.2015.05.035

Birkmann J, Cutter SL, Rothman DS, et al (2015) Scenarios for vulnerability: opportunities and constraints in the context of climate change and disaster risk. Clim Change 133:53-68 . doi: 10.1007/s10584-013-0913-2

Camargo SJ (2014) Global and Regional Aspects of Tropical Cyclone Activity in the CMIP5 Models. J Clim. doi: 10.1175/JCLI-D-12-00549.1

Chang C-H (2011) Preparedness and storm hazards in a global warming world: lessons from Southeast Asia. Nat Hazards 56:667-679 . doi: 10.1007/s11069-010-9581-y

Conway D, Mustelin J (2014) Strategies for improving adaptation practice in developing countries. Nat Clim Chang 4:339-342 . doi: 10.1038/nclimate2199

Coumou D, Rahmstorf S (2012) A decade of weather extremes. Nat Clim Chang 2:491 . doi: 10.1038/nclimate1452

CRDI (2013) Levels and Sources of Household Income in Rural Cambodia 2012. Phnom Penh, Cambodia

DanChurchAid/Christian Aid (DCA/CA) (2011) Climate Change and Disaster Management Policy Mapping and Analysis in Cambodia

Giorgi F, Gutowski WJ (2015) Regional Dynamical Downscaling and the CORDEX Initiative. Annu Rev Environ Resour 40:467-90 . doi: 10.1146/annurev-environ-102014-021217

Gollier C (2001) Should we beware of the precautionary principle? Econ Policy

Halsnæs K, Kaspersen PS, Drews M (2015) Key drivers and economic consequences of high-end climate scenarios: Uncertainties and risks. Clim Res 64:85-98 . doi: 10.3354/cr01308

Harmeling S, Eckstein D, eV G (2012) Global Climate Risk Index 2013. Bonn

Hawkins E, Sutton R (2009) The Potential to Narrow Uncertainty in Regional Climate Predictions. Bull Am Meteorol Soc 90:1095-1107 . doi: 10.1175/2009BAMS2607.1

Heal G, Kriström B (2002) Uncertainty and climate change. Environ. Resour. Econ.

Hemer MA, Trenham CE (2016) Evaluation of a CMIP5 derived dynamical global wind wave climate model ensemble. Ocean Model 103:190-203 . doi: 10.1016/j.ocemod.2015.10.009

Herrmann M, Somot S, Calmanti S, et al (2011) Representation of spatial and temporal variability of daily wind speed and of intense wind events over the Mediterranean Sea using dynamical downscaling: Impact of the regional climate model configuration. Nat Hazards Earth Syst Sci. doi: 10.5194/nhess-11-1983-2011

International Statistics Institute (2018) Developing Countries. https://www.isiweb.org/index.php/resources/developing-countries. Accessed 29 May 2018

IPCC (2014a) Climate Change 2014: Impacts, Adaptation, and Vulnerability. Contribution of 
Working Group II to the Fifth Assessment Report of the Intergovernmental Panel on Climate Change. Cambridge University Press, United Kingdom and New York, NY, USA, 1132 pp IPCC (2014b) Summary for Policymakers. In: Climate Change 2013: The Physical Science Basis. Contribution of Working Group I to the Fifth Assessment Report of the Intergovernmental Panel on Climate Change. [Stocker, T.F., D. Qin, G.-K. Plattner, M. Tignor, S.K. Allen. Cambride University Press, Cambridge, United Kingdom and New York, NY, USA

IPCC (2014c) Climate Change 2014: Mitigation of Climate Change. Contribution of Working Group III to the Fifth Assessment Report (AR5) of the Intergovernmental Panel on Climate Change (IPCC). Cambridge University Press, United Kingdom and New York, USA

IPCC (2005) Guidance Notes for Lead Authors of the IPCC Fourth Assessment Report on Addressing Uncertainties. Intergov Panel Clim Chang. doi: 10.1007/BF02986817

IPCC (2007) Climate change 2007: Impacts, adaptation and vulnerability : Working Group II contribution to the Fourth Assessment Report of the IPCC Intergovernmental Panel on Climate Change. Cambridge University Press, Cambridge, UK

Jiang Y, Luo Y, Zhao Z, et al (2010) Projections of wind changes for 21st century in China by three regional climate models. Chinese Geogr Sci. doi: 10.1007/s11769-010-0226-6

Jin CS, Cha DH, Lee DK, et al (2016) Evaluation of climatological tropical cyclone activity over the western North Pacific in the CORDEX-East Asia multi-RCM simulations. Clim Dyn. doi: 10.1007/s00382-015-2869-6

Jury MW, Prein AF, Truhetz H, Gobiet A (2015) Evaluation of CMIP5 models in the context of dynamical downscaling over Europe. J Clim. doi: 10.1175/JCLI-D-14-00430.1

Katz RW (2010) Statistics of extremes in climate change. Clim Change 100:71-76 . doi: 10.1007/s10584-010-9834-5

Knapp KR, Kruk MC, Levinson DH, et al (2010) The International Best Track Archive for Climate Stewardship (Ibtracs) Unifying Tropical Cyclone Data. Bull Am Meteorol Soc. doi: 10.1175/2009BAMS2755.1

Kumar D, Mishra V, Ganguly AR (2015) Evaluating wind extremes in CMIP5 climate models. Clim Dyn 45:441-453 . doi: 10.1007/s00382-014-2306-2

Kunz M, Mohr S, Rauthe M, et al (2010) Assessment of extreme wind speeds from regional climate models - Part 1: Estimation of return values and their evaluation. Nat Hazards Earth Syst Sci. doi: 10.5194/nhess-10-907-2010

Larsen MAD, Thejll P, Christensen JH, et al (2013) On the role of domain size and resolution in the simulations with the HIRHAM region climate model. Clim Dyn 40:2903-2918 . doi: 10.1007/s00382-012-1513-y

Markandaya A (1998) Economics of Greenhouse Gas Limitations. The indirect costs and benefits of greenhouse gas limitations

Ministry of Environment (2005) Vulnerability and Adaptation to Climate Hazards and to Climate Change: A survey of rural Cambodian households

Ministry of Environment (2006) NATIONAL ADAPTATION PROGRAMME OF ACTION TO CLIMATE CHANGE (NAPA)

Ministry of Planning (2012) Identification of Poor Households - CAMBODIA Results from Data Collection Rounds 4 (2010) and 5 (2011)

Møller LR, Drews M, Larsen MAD (2017) Simulation of Optimal Decision-Making Under the Impacts of Climate Change. Environ Manage. doi: 10.1007/s00267-017-0852-1

Mora C, Frazier AG, Longman RJ, et al (2013) The projected timing of climate departure from recent variability. Nature 502:183-187 . doi: 10.1038/nature12540

Munich RE (2018) NatCatSERVICE. http://natcatservice.munichre.com/. Accessed 5 Mar 2018

National Institute of Statistics (2013) Cambodia inter-censal population survey 2013

Onuma H, Shin KJ, Managi S (2017) Reduction of future disaster damages by learning from disaster 
experiences. Nat Hazards 87:1435-1452 . doi: 10.1007/s11069-017-2825-3

Patt AG, Tadross M, Nussbaumer P, et al (2010) Estimating least-developed countries' vulnerability to climate-related extreme events over the next 50 years. Proc Natl Acad Sci U S A 107:1333-7 . doi: 10.1073/pnas.0910253107

Penning-Rowsell EC, Sultana P, Thompson PM (2013) The 'last resort'? Population movement in response to climate-related hazards in Bangladesh. Environ Sci Policy 27:S44-S59 . doi: 10.1016/j.envsci.2012.03.009

Pryor SC, Nikulin G, Jones C (2012) Influence of spatial resolution on regional climate model derived wind climates. J Geophys Res 117:

Púčik T, Groenemeijer P, Rädler AT, et al (2017) Future changes in European severe convection environments in a regional climate model ensemble. J Clim. doi: 10.1175/JCLI-D-16-0777.1

Ren D, Leslie LM (2015) Changes in tropical cyclone activity over Northwest Western Australia in the past 50 years and a view of the future 50 years. Earth Interact. doi: 10.1175/EI-D-14-0006.1

Rockel B, Woth K (2007) Extremes of near-surface wind speed over Europe and their future changes as estimated from an ensemble of RCM simulations. Clim Change. doi: 10.1007/s10584-0069227-y

Taylor KE, Stouffer RJ, Meehl GA (2012) An overview of CMIP5 and the experiment design. Bull. Am. Meteorol. Soc.

Tobin I, Jerez S, Vautard R, et al (2016) Climate change impacts on the power generation potential of a European mid-century wind farms scenario. Environ Res Lett. doi: 10.1088/17489326/11/3/034013

UNDP (2015) National Committe for Disaster Management. http://camdi.ncdm.gov.kh/DesInventar/profiletab.jsp. Accessed 2 Feb 2018

United Nations (2018) Least Developed Countries (LDCs). https://www.un.org/development/desa/dpad/least-developed-country-category.html. Accessed 29 May 2018

Vermeulen SJ, Challinor AJ, Thornton PK, et al (2013) Addressing uncertainty in adaptation planning for agriculture. Proc Natl Acad Sci U S A 110:8357-62 . doi: 10.1073/pnas.1219441110

Wahl T, Jain S, Bender J, et al (2015) Increasing risk of compound flooding from storm surge and rainfall for major US cities. Nat Clim Chang 5:1093-1097 . doi: 10.1038/nclimate2736

Wei Y-M, Wang K, Liao H, Tatano H (2016) Economics of climate change and risk of disasters in Asia-Pacific region. Nat Hazards 84:1-5 . doi: 10.1007/s11069-016-2590-8

Weitzman ML (2011) Fat-Tailed Uncertainty in the Economics of Catastrophic Climate Change. Rev Environ Econ Policy 5:275-292 . doi: 10.1093/reep/rer006

World Bank (2017) World Development Indicators 2017. Washington, DC

Young IR, Zieger S, Babanin A V (2011) Global trends in wind speed and wave height. Science 332:451-5 . doi: 10.1126/science.1197219

Zou L-L, Wei Y-M (2010) Driving factors for social vulnerability to coastal hazards in Southeast Asia: results from the meta-analysis. Nat Hazards 54:901-929 . doi: 10.1007/s11069-010-9513$\mathrm{X}$ 